\title{
CASE REPORT: SUPERIOR VENA CAVA SYNDROME SECONDARY TO INTRATHORACIC GOITER
}

\section{Bruno Francisco García-Bray', Nieves Cruz Felipe-Pérez², Ricardo Darias-Garzón², Benigno Rivero-Melián², Ignacio Llorente- Gómez de Segura²}

1 Hospital San Juan de Dios, Tenerife, Endocrinology and Nutrition Department, Spain

${ }^{2}$ Hospital Universitario Nuestra Señora de la Candelaria, Endocrinology and Nutrition Department, Tenerife, Spain

\section{Introduction}

We introduce a case involving the appearance of superior vena cava syndrome secondary to intrathoracic goiter. We discuss the diagnosis, prognosis and treatment applied to this pathology.

\section{Case Report}

67 year old woman who presents respiratory distress, cough and weight loss. After physical examination and a chest radiography showing a mass that occupied the upper and middle right lung lobes, a superior vena cava syndrome due to a neoplasm is suspected and at first, palliative radiotherapy is indicated. Chest and abdomen CT are done before treatment and an intrathoracic goiter is diagnosed. Fine needle eco-guided aspiration was attempted, not retrieving proper representative material, and not repeated due the intense vascularization of the gland. Bronchoscopy was performed, also showing bilateral vocal cord paralysis and longitudinal tracheal stenosis, being the cytological sample (obtained by aspiration and brush biopsy) negative for malignant tumor cells. Following this finding, surgical treatment is performed. The anatomopathologycal study of the excised material described a colloid adenomatous goiter without histological signs of malignancy. The patient was discharged, attending her first review visit 4 months later, having at the time persistent dysphonia but an overall clinical improvement.

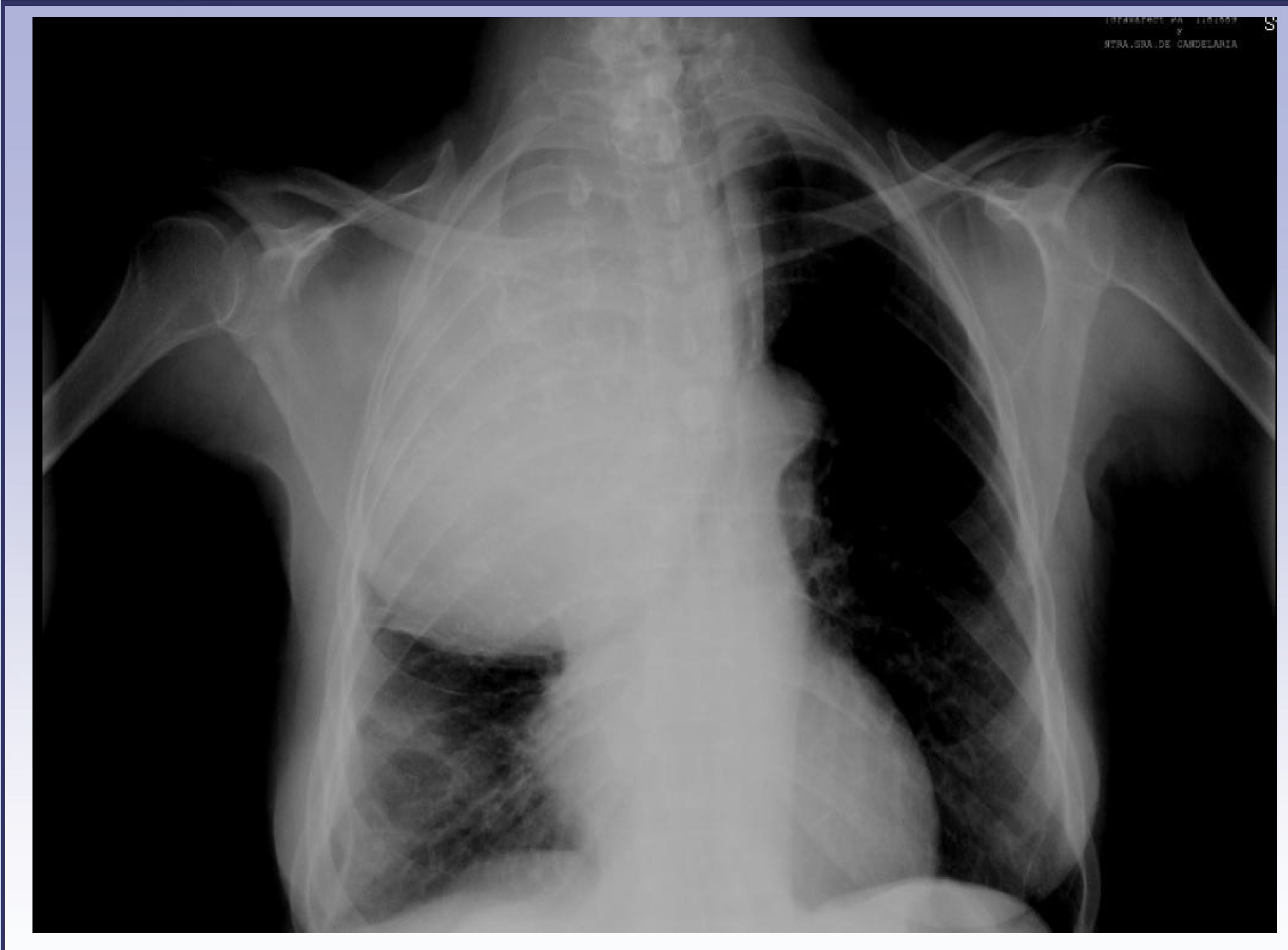

Chest radiography performed in the emergency area, showing a mass that occupies the upper and middle right lung lobes, with contralateral displacement of the trachea.

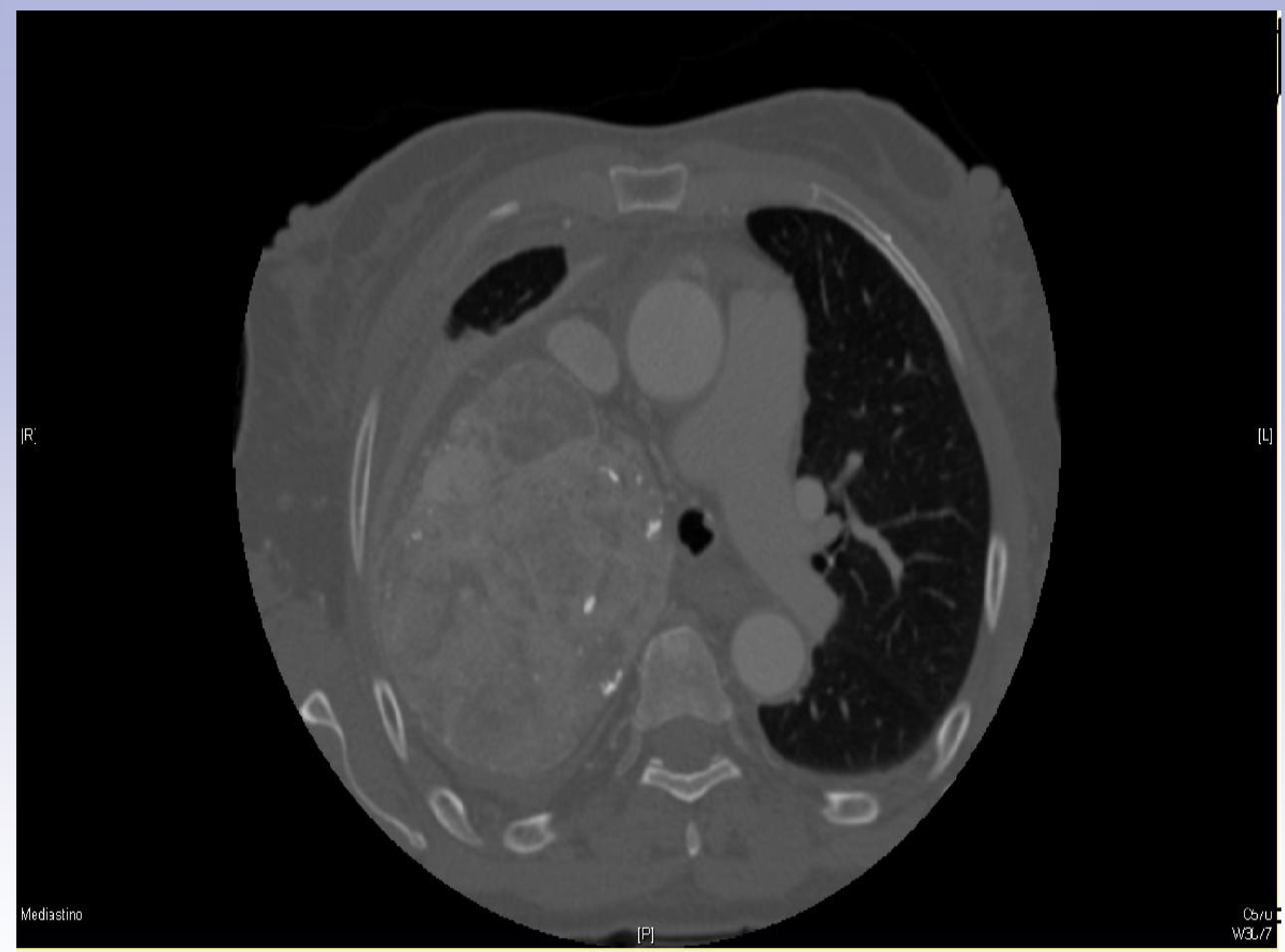

Chest CT showing right lung atelectasis and a multinodular thyroid mass with calcifications and an intrathoracic extension up to the right superior pulmonary vein which displaces and compresses the trachea.

\section{Conclusions}

When a superior vena cava syndrome is diagnosed, additional tests should be performed to discover the real ethiology of the syndrome, which in this case corresponds to a giant intrathoracic goiter. Thyroid function tests and imaging techniques such as ultrasound or CT are indicated in these cases. The treatment of choice of the intrathoracic goiter is surgical removal, especially in cases where compression of adjacent structures is present. The most common complications after thyroidectomy are: recurrent laryngeal nerve injury, superior laryngeal nerve injury, transient or permanent hypoparathyroidism, hypothyroidism, bleeding, respiratory infections and tracheomalacia. As for treatment with radioactive iodine, reductions on gland size have been described. However, this possibility must be evaluated carefully, taking into account the high risk of thyroiditis with the consequent worsening of compressive symptoms, dysphagia and pain.

\section{Bibliography}

\footnotetext{
1. Ríos A, Sitges-Serra A. Tratamiento quirúrgico del bocio intratorácico. Cirugia Española 201290 421-8

2. Aguiar-Quevedo K, Cerón-Navarro J, Jordá-Aragón C, Pastor-Martínez E, Sales-Badia JG, García-Zarza A,Pastor-Guillén J. Intrathoracic goitre: a literature review. Cirugia Española 2010 88(3) 142-5

3. Ríos A, Rodríguez JM, Balsalobre MD, Tebar FJ, Parrilla P. The value of various definitions of intrathoracic goiter for predicting intra-operative and postoperative complications. Surgery $2010147233-8$

4. Newman E, Shaha AR. Substernal goiter. Journal of Surgical Oncology $199560(3) 207-12$.

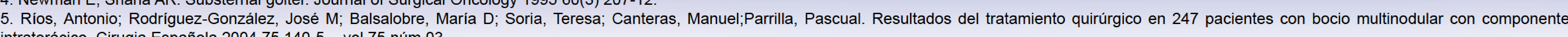
intratorácico. Cirugia Española 200475 140-5. - vol.75 núm 03

6. Hegedüs L, Bonnema S. Approach to Management of the Patient with Primary or Secondary Intrathoracic Goiter. The Journal of Clinical Endocrinology \& Metabolism 2010 95(12) 5155-5162. 7. Foroulis C, Rammos K, Sileli M, Papakonstantinou C. Primary Intrathoracic Goiter: A Rare and Potentially Serious Entity. Thyroid 2009 19(3) 213-8.
} 